\title{
UAE University Male Students' Interests Impact on Reading and Writing Performance and Improvement
}

\author{
Ghadah Al Murshidi ${ }^{1}$ \\ ${ }^{1}$ Faculty of Education, Curriculum and Instruction Department, UAE University, UAE \\ Correspondence: Ghadah Al Murshidi, Faculty of Education, Curriculum and Instruction Department, UAE \\ University, UAE. E-mail: g_almurshidi@uaeu.ac.ae
}

Received: May 6, 2014 Accepted: June 6, 2014 Online Published: August 14, 2014

doi:10.5539/elt.v7n9p57 URL: http://dx.doi.org/10.5539/elt.v7n9p57

\begin{abstract}
The study examined the impact of the conjunction of structured journal writing and reading for pleasure on students' reading and writing skills. Forty male students from UAE University participated in the study. The participants are of different academic abilities, majors and nationalities. Many of them have little experience with reading for pleasure and reflective writing. They were advised to select interested academic articles they would like to read and then reflect on the articles in their journals by filling different types of maps and summarizing the main points in the articles. The data includes the students' interviews. The study explored whether the approach positively affects students' academic reading and writing and helps students overcome their reading and writing anxiety. The study results are relating topics to students' major deepen the students' knowledge in their specialization. Selecting topics of students' interests encourages them to continue working on reading the articles even though they face some challenges. Content and organization in reading and writing were improved in students' dialogue journals project and story mapping strategy. The students' awareness of building a large vocabulary is significant. However, students 'fear of making semantic errors in their writing delays their work. Knowledge and experience gain, creativity and personality improvement are indicators of students' enjoyment of reading and writing topics of their choices and interest even though they struggled initially.
\end{abstract}

Keywords: male students, UAE University, academic articles reading, academic writing, students' choices and interest

\section{Introduction}

English Writing is one of the most important skills that students are taught at universities because "in order to handle academic tasks, ESL students need to do their best to write proficiently" (Ghabool, Mariadass, \& Kashef, 2012, p. 132). Conley (1995) affirmed that writing makes our thoughts and experiences vivid and long lasting and helps us learn things in every subject area. (Ibaninan, 2010, p. 181) Many English teachers take it for granted that writing a paragraph or even an essay should be an easy task for their students. Teachers enter their classes, assign challenging writing topics and expect students to write coherent, unified paragraphs that are accurate grammatically.

What makes things harder on students is that they have to write in a foreign language (English). When teachers take their pens to check students' papers, they tend to assume the role of a surgeon who is about to dissect a corpse. The frustration of students arises when they do their best to write a paragraph or an essay, yet they do not get the score that they aspired to. That is because their piece of writing did not meet the academic writing criteria that their teacher had set. Students are expected to write in all different subjects though these students are seldom taught "how to write." This approach has led many students to hate writing simply because the whole experience is not rewarding. Many students have even developed writing anxiety "a distinct complex of self-perceptions, beliefs, feelings, and behaviors related to classroom language learning” (E. Horwitz, M. Horwitz, \& Cope, 1986, p. 128).

One of the strategies that can help students overcome their writing anxiety and improve their writing scores is through reading interesting topics to them and journal writing. "The reading-writing relation is a strong one. Suitable reading material, when used creatively can enhance the writing curriculum. Students who are exposed to many genres and styles of good literature are very likely to transfer these rich experiences to their own writing." 
(Olness, 2005, p. 9) Avid readers would most likely become good writers "as they become familiar with article elements, terminology, and style, students begin to include them in their own writing." (Olness, 2005, p. 3) Journal writing is another instructional strategy that can assist students overcome their writing anxiety.

\section{Statement of the Problem}

The writing proficiency of some male students in the UAE University is way below the international standards. One of the main challenges these students face is the lack of English language proficiency which "is the main cause of lots of difficulties that ESL learners have in their writing tasks" (Gabool, Edwina, \& Kashef, 2012, p. 132). These language difficulties make students dislike reading and wiring in their academic disciplines, which affects negatively in their performance. Students need more encouragement to read and consequently improve their writing skills. Most of the students do not consider reading as part of their daily routine which reflects on the quality of the writing pieces they produce. Considering students' interests to be a key for encouraging them to read and write, could be beneficial. Giving students the freedom to choose topics that are in their interests, to read academic articles and write in academia using story mapping as strategy could motivate the students to enjoy academic reading and writing in their academic fields.

\section{Purpose of the Study}

Teachers are trying to enhance students' writing skills. They have attained some success but that is incomparable to the efforts and time the teachers have invested. The researcher realizes that students' improvement in writing will significantly impact their academics in general and their language skills in particular. The urgency and importance of the issue has led the researcher to think of a technique that would engage the students and minimize the pressure on the language arts teachers who generally agree that teaching writing is a daunting task. The purpose of the study is to explore the effectiveness of the use of approach which includes using reading academic articles that are chosen by the students based on their interests and structured journal writing to enhance the performance of forty male students at UAE University in Al-Ain.

\section{The Research Questions}

The research questions are:

1) What is the impact of using the instructional strategy of reading topics of students' choices and interests and academic writing on changing students' negative attitude toward writing?

2) What are the students' challenges of using the instructional strategy of reading topics of students' choices and interests and academic writing?

\section{Significance of the Study}

Although studies that explore the importance of reading articles relevant to students' interest and journal writing as instructional strategies to improve students' writing fluency are abound, relatively few studies have investigated the effect of using reading interesting topics and mapping in students' journals as facilitative tools that can help improve students' writing skill.

English language proficiency is a key to students' success at UAE University and the lack of this essential skill can impede students' academics. The implementation of reading interesting topics and journal writing approach will not merely affect students' English competence but will also have positive impact on their future careers.

The study is significant for students. The study could propose some strategies that assist students overcome their writing anxiety. As a long term effect, students will become better readers and more confident writers. Some teachers consider writing the most challenging skill to teach. The study could help teachers by introducing new instructional strategies that will contribute to students' writing skills improvement.

\section{Literature Review}

In the 21 st century, reading and writing is significant in human history. Students need advanced levels of literacy to perform their careers, run their households, act as citizens, and conduct their personal lives. They need literacy to cope with the information they find everywhere. They need literacy to feed their imaginations to build the future (Moore, Bean, Birdyshaw, \& Rycik, 1999).

Many students view reading and writing as boring tasks that their teachers force them to perform. In most of the undergraduate courses, teachers ask students to read academic articles. Students often complain about the difficult academic articles they read in class. Teachers have to adhere to the curriculum standards. Invariably students complain that generating ideas for their writing tasks is a real challenge.

A new approach is crucial to change students' negative attitude toward reading and writing. For instance, reading 
academic articles that are relevant to their interest and journal writing using the story mapping strategy could help improving students' attitude toward reading and writing as Ghazali (2009) stated that students' attitude is essential in maintaining their success in language learning.

Reading interesting topics is beneficial for students as Krashen (1993) emphasized that when students read for pleasure and get "hooked on books", they acquire, involuntarily and without conscious effort, language skills. The students become adequate readers, acquire a large vocabulary, develop the ability to understand and use complex grammatical constructions, develop a good writing style, and become good spellers.

To enhance students' writing skills, reading academic articles of students' choice and interest can be used in conjunction with journal writing. Herroro (2007) conducted a study that explored the positive relationship between reading and journal writing. Twenty three university students kept "a journal that included a personal dictionary and a reading log." (p. 7), engaged "in two types of reading: extensive and intensive reading." (p. 8) and responded to prompts on daily basis. The teacher provided constructive feedback for the students regarding their performance and utilized the scaffolding process to promote students' learning by providing a handout with rules and exercises. Herroro (2007) analyzed the students' errors and monitored their progress. Herroro (2007) emphasized that students' awareness of building a large vocabulary and extensive reading is important to become good readers and writers. Herrero (2007, p. 24) added:

It is significant for the students to enjoy what they are reading. Although it is difficult to please everybody, professors should choose books appropriate for the age, interests, and proficiency level of the students. If a student does not like the theme or the type of book assigned, teachers should give them alternatives in order to get better results

Journal writing develops students' writing skills because it encourages the students to express their views about the articles they read, utilize the language learned in the readings in a real context. Students' journals provided authentic samples of students' work which assist the teacher to pinpoint content and linguistic problems and provide individual and group feedback that can be individualized to the students' needs (Herrero, 2007).

Tuan (2010) providing feedback to students' journal entries enable teachers to measure each learner's proficiency and understand their needs, thoughts, and feelings, which assist teachers modify their teaching styles to meet learners' preferences and assist them in their writing difficulties.

Liao and Wong (2008) study of dialogue journals project emphasized that students' writing fluency, writing performance on content, organization, and vocabulary; reflective awareness of writing and self-growth as learners, and intrinsic writing motivation, were improved.

Imposing assignment of Reader's Journals in which students write informal responses to reading assignment is recommended rather than quizzes which students' fear. It makes students relax and do not worry about text organization, spelling and grammar because it is not graded. Journal writing is instructional effective tool that assists students overcome their reading and writing anxieties and motivates them to perform their reading, which it differs than traditional reading strategies (August, 2000).

Ibanian (2010) study proved that the story mapping strategy had a positive influence on developing students' writing skills in terms of content, organization, mechanics of writing, language use, fluency, flexibility, novelty and elaboration. The story mapping promotes students' competency to recognize main story ideas and elements to compose well-formed narratives (Baumann \& Bergeron, 1993).

\section{Research Methodology}

This study employed a qualitative research design to examine the impact of reading academic articles topics based on the students' interests, choices, journal writing on students' reading and writing performance.

The study took place in the UAE University in Al-Ain, which English is the medium of instruction for nearly all subjects. Some of the male students in the University are not fluent English language speakers and a considerable number of these students find writing a challenging skill to master. In writing, some students translate from Arabic to English.

The Introduction to Language and Communication Course was taught to forty male students who are from different colleges (e.g., Engineering, business, Social Sciences and Humanities, Law, Science, etc.) and different years (first, second, third, fourth, fifth year). Their ages range between 20 and 25 . These students are with different academic abilities and varying English language proficiency.

The procedures of this study are students chose academic articles topics related to their specializations and interests about language and Communication issues to read. The students used different types of reading maps 
and reflected on the academic articles they read by writing their dialog journals and present in classroom.

In this study, the data collection tool that the researcher used is interviewing six male students. The researcher conducted open-ended interviews with male students on regular basis in order to monitor their progress and receive feedbacks with regards to the interesting articles they are reading and journals they are writing. The questions of the interviews focus on the researcher's newly introduced strategy and aim at receiving participants' feedbacks towards the newly adopted technique and the impact it had on their attitude toward reading and writing and whether it has improved their reading and writing.

\section{Results and Discussion}

This section presents some of the findings and discussion of the interviews analysis to its themes based on the research questions. The main results of research Question 1: What is the impact of using the instructional strategy of reading topics of students' choices and interests and academic writing on changing students' negative attitude toward writing? Are as followed:

\subsection{Benefits of Choosing Topics of Student's Interest}

UAE University male students expressed their ownership of the topics that they have chosen and how their choices make a difference in their learning. As Byerikbolsy commented:

It is interesting to know world of politics that I just start to learn. I chose my topic that is related to my political science major.

Shuaib added:

The most interested thing in choosing my topic was that I gain more knowledge and information. It opens my mind to different cultures and even become interested in knowing what the world is all about especially in terms of language and communication. I have learnt that a person can learn at any time and any place and age. Interest is the most significant.

\subsection{Knowledge Gain}

Feeling of the work significance came after students' knowledge gain as Mohammed commented:

The struggles I came across have made me realize the importance of the work I do and increased my knowledge capacity.

Abdullah added:

I have learned and gained more knowledge, experience and information during searching for my chosen topic.

\subsection{Improving Reading Skills and Patience}

Students' own choices encouraged them to continue reading even though the difficulty of the reading texts. As Mohammed commented:

Choosing my interested topic and its challenges have helped me in earning great skills of reading and searching, being patient until finding the right information and working on different sources of information to obtain accurate details about the topic I am writing.

\subsection{Improving Vocabulary and Writing Skills}

Reading topics of students' choices and interests improved their vocabulary and generally writing skills as Mohammed commented:

I have developed better writing skills and selecting appropriate formal words which in turn has improved my English vocabulary.

\subsection{Improving Critical Thinking Skills}

Reading more in a chosen topic deeply improves students' critical thinking skills as Mohammed commented:

I have become capable of criticizing and analyzing various aspects of similar topics due to reading and thinking about different opinions of international writers and novelists.

\subsection{Making Effort for Creativity}

Some students expressed their enjoyment in the process of searching for their interested topics, analyzing and presenting, which gave them feeling of comfort and confidence as Mthkar commented:

If I choose my own topic which is I liked. I did my best to create new ideas. I was creative in analyzing my topic. It was easier to talk about my topic. When I got questions from the students, I answered easily. 


\subsection{Personality Development}

Personality development is an advantage of reading preferred topics as Mohammed commented:

The work of choosing my own topic has helped me in developing my own character and thinking skills.

This section presents the main results and discussion of research Question 2: What are the students' challenges of using the instructional strategy of reading topics of students' choices and interests and academic writing? are as followed:

\subsection{Not Meeting Students' Interests}

Other students started to think of their classmates' interest to attract their attention in their presentations. As Mthkar commented:

I thought may be the students will not like my topic or it is not their preference.

Mohammed added:

It was not easy to select important and beneficial topics that may be of major concern to many students

\subsection{Difficulty in Finding the Accurate Information}

Other students face challenges in searching for the suitable information related to their topics. As Byerikbolsy commented:

I am student of Political Science department so everything that happens in the world is very interesting for me. When I wrote about The Formation of UN, it was very difficult to find out when exactly it started and how it was developed. It was a challenge for me to find correct answers and to find correct date in a history.

Mohammed added:

The challenges I have experienced during selecting desired topics were ways of information gathering either through books, articles or internet.

\subsection{Information Organization}

During the reading process, some students thought deeply in organizing the collected ideas which they found it challenging.

Mohammed commented:

Organizing relevant information and details according to their priority order was difficult for me when I selected my interested topic.

\subsection{Difficulty in Paraphrasing Paragraphs}

During the writing process, some students found it difficult to paraphrase the ideas that they read from the related articles As Mohammed commented:

I found difficulty in paraphrasing certain paragraphs to provide a better and clearer understanding of the topic.

8.12 Fear of Spelling, Vocabulary and Grammatical Errors

Students' fear of making technical errors in their writing about their topics delays their work. As Mohammed commented:

Avoiding spelling, vocabulary and grammatical errors while writing for my topic that I have selected was a challenge.

\subsection{More Effort and Time to Do the Work}

Some students felt exhausted of the time spent to search for the related articles to their chosen topics. As Mthkar commented:

When I chose my own topic which is interested for me, I thought I might not find information related to my topic. I need to do more work and effort to collect the most relevant information to my topic. I asked my classmate to get more opinions about my topic.

Mohammed added:

When I chose my interested topic, I faced some struggles. These struggles made my work uneasy and require time to find the most appropriate materials that are relevant to my selected topic. 


\section{Discussion and Conclusion}

Relating topics to students' major deepen the students' knowledge in their specialization As Byerikbolsy commented. Students' beliefs that learning possibility without limits, and their interests and openness to other cultures differences is stated by Shuaib: "I have learnt that a person can learn at any time and any place and age. Interest is the most significant".

Selecting topics of students' interests encourages them to continue working on reading the articles even though they face some challenges as Mohammed commented: "it requires time to find the most appropriate materials" and Mthkar added: "I need to do more work and effort to collect the most relevant information to my topic". Mohammed stated: "Choosing my interested topic...have helped me in ... being patient until finding the right information".

Content and organization in reading and writing were improved in students' dialogue journals project (Liao \& Wong, 2008) and story mapping strategy (Ibanian, 2010). When these strategies were used with the male UAE University students, the students initially found the strategies challenging, which means that students' reflective awareness of writing and self-growth as learners were improved as Mohammed commented: "Organizing relevant information and details according to their priority order was difficult for me when I selected my interested topic".

The students' awareness of building a large vocabulary is significant (Herroro, 2007). When students read for pleasure and choose their interesting topics, they acquire a large vocabulary (Krashen, 1993). Also, students' vocabulary improved when they write their dialogue journals (Liao \& Wong , 2008) as Mohammed commented: "I have developed better writing skills and selecting appropriate formal words which in turn has improved my English vocabulary". However, students "fear of making semantic errors in their writing delays their work As Mohammed commented: "Avoiding spelling, vocabulary ... errors while writing ... was a challenge".

As initial stage, Knowledge and experience is what the students gained as Mohammed commented: "The struggles I came across have....increased my knowledge capacity". Abdullah added: "I ... gained more knowledge, experience" In later stages, students developed skills of critical thinking as Mohamed emphasized "I have become capable of criticizing and analyzing various aspects of similar topics".

Creativity and personality improvement are indicators of students' enjoyment of reading and writing topics of their choices and interest even though they struggled initially As Mathkr commented: "If I choose my own topic which is I liked. I did my best to create new ideas" and as Mohammed commented: "choosing my own topic has helped me in developing my own character".

The role of reading interesting articles, article mapping and journal writing in enhancing students' reading and writing performance is important, which is preferable to students rather than traditional approaches that some teachers utilize. The reading and writing performance of the male students who are instructed using the conjunction of reading their interesting topics and writing structured journal is improved. The implementation of this approach empowers the students, help them overcome their writing anxiety and ultimately improve their achievement in their reading and writing. This study is beneficial to students, teachers and researchers. Based on the study results, adopting this approach, teachers could assist their students overcome their writing anxiety which could lead to students' writing skills improvement. The results of this study emphasize that when the students are given the opportunity to read academic articles they choose and like, they most probably develop a love for reading and writing. When these students start to find a pleasure in reading, they most probably become lifetime readers, a target that many teachers aspire to attain. This passion for reading assists students improving their reading and writing skills. The study shed light on the significance of reading academic articles of the students' choices and interest and academic writing. Further studies would be needed to search for other instructional strategies of improving students' reading academic articles and writing skills.

\section{References}

August, A. (2000). The Reading Journal in Lower-Division History Classes. The History Teacher, 33(3), 343-248.

Baumann, J. F., \& Bergeron, B. S. (1993). Story map instruction using children's literature: Effects on first graders' comprehension of central narrative elements. Journal of Reading Behavior, 25(4), 407-437.

Gay, L. R., Mills, G., \& Airasian, P. (2011). Educational Research: Competencies for Analysis and Applications. New Jersy: Pearson Education International. 
Ghabool, N., Edwina, M., \& Kashef, H. S. (2012). Investigating Malaysian ESL Students' Writing Problems on Conventions, Punctuation, and Language Use at Secondary Level. Journal of Studies in Education, 2(3), 131-143.

Ghazali, S. N., Chittra, M., \& Jusoff, K. (2009). ESL Students' Attitude towards Texts and Teaching Methods Used in Literarture Classes. English Language Teaching, 2(4), 51-56.

Herrero, A. H. (2007). Journals: A Tool to Improve Students' Writing Skills. Actualidades Investigativas en Educación, 7(1), 1-37.

Horwitz, E. K., Horwitz, M. B., \& Cope, J. (1986). Foreign Language Classroom Anxiety. The Modern Language Journal, 70(2), 125-132.

Ibnian, S. S. (2010). The Effect of Using the Story-Mapping Technique on Developing. English Language Teaching, 3(4), 181-194.

Lalande, J. F. (1982). Reducing Composition Errors: An Experiment. Modern Language Journal, 66(1), 140-149.

Liao, M. T., \& Wong, C. T. (2008). Effects of Dialogue Journals on L2 students' Writing Fluency, Reflection, Anxiety, and Motivation. Reflections on English Language Teaching, 9(2), 139-170.

Larsen-Freeman, D. (2003). Teaching Language: From Grammar to Grammaring. Boston: Thomson-Heinle.

Moore, D. W., Bean, T. W., Birdyshaw, D., \& Rycik, J. A. (1999). Adolescent literacy: A position statement. Journal of Adolescent \& Adult Literacy, 43(1), 97-112.

Miceli, T. (2006). Foreign Language Students' Perceptions of a Reflective Text Approach to Correction. Flinders University Languages Group Online Review, 3(1), 25-36.

Olness, R. (2005). Using Literature to Enhance Content Area Instruction: A Guide for K-5 Teachers. Newark, DE: International Reading Association.

Petric, B. (2002). Students' Attitudes towards Writing and the Development of Academic Writing skills. Writing Center Journal, 22(2), 9-27.

Srichanyachon, N. (2012). Teacher Written Feedback for L2 Learners' Writing Development. Silpakorn University Journal of Social Sciences, Humanities, and Arts, 12(1),1-17.

Tuan, L. T. (2010). Enhancing EFL Learners' Writing Skill via Journal Writing. English Language Teaching, $3(3), 81-88$.

White, R., \& Arndt, V. (1991). Process Writing. London: Essex: Addison Wesley Longman Ltd.

\section{Copyrights}

Copyright for this article is retained by the author(s), with first publication rights granted to the journal.

This is an open-access article distributed under the terms and conditions of the Creative Commons Attribution license (http://creativecommons.org/licenses/by/3.0/). 